\title{
The Effects of Three L2 Vocabulary Learning Methods Through Reading Activity
}

\author{
Keita Kodama \\ jody@ccalumni.meijo-u.ac.jp \\ Faculty of Foreign Studies, Meijo University \\ $\&$ \\ Tomohiko Shirahata \\ shirahata.tomohiko@shizuoka.ac.jp \\ Faculty of Education, Shizuoka University
}

\section{Article History}

Received: 29-10-20

Reviewed: 11-05-21

Accepted: 13-05-21

\section{Keywords:}

learning of L2 vocabulary learning vocabulary through reading activity

explicit and implicit learning

\section{DOI:}

https://doi.org/10.33508/bw.v9i1.2778

\begin{abstract}
This study examines the effectiveness of the three vocabulary learning methods the authors adopted. In search of this research issue, the study used longitudinal experiments with 93 university Japanese learners of English (JLEs) for fifteen weeks. Once a week for six consecutive weeks, participants of the three experiment groups were given different treatments for learning 110 targeted English words when they were mainly reading an English textbook: (i) Group A: the Implicit Vocabulary Learning Group with Questions in English/Answers in English Task, (ii) Group B: the Explicit Vocabulary Learning Group with a Cloze Test Task, and (iii) Group C: the Explicit Vocabulary Learning Group with Multiple-choice Word Test Task. A pretest, immediate posttest, and delayed posttest were conducted. The results showed that (i) all the groups improved their performances at the immediate posttest and almost maintained their performance levels at the delayed posttest, which indicate that all the learning methods were more or less effective. However, the developmental degrees of the vocabulary increase were different: Group C showed the highest improvement among the three. From these findings, the authors claim that using a (multiple-choice) word test is fairly effective for JLEs to develop their knowledge of English words.
\end{abstract}

\section{Introduction}

The authors' ultimate purpose is to find out the most effective learning/teaching method of second language (L2) vocabulary learning in Japan. As the first step for achieving the purpose, the present study examines the effectiveness of the three vocabulary learning methods the authors adopted: which is the most effective method for Japanese learners of English (JLEs) to learn English words through reading activities in the classroom. The authors designed and conducted three longitudinal experiments. Each experiment had a different learning method of L2 vocabulary.

The authors believe that vocabulary plays a fundamental role for developing L2 
learners' four skills: speaking, writing, reading and listening. Without the knowledge of vocabulary, we would not practice any linguistic activity and cannot communicate with others. It seems true that people with plenty of vocabulary knowledge will speak and write logically and think deeply in order to express their ideas accurately. Moreover, under the new Course of Study by the Ministry of Education, Culture, Sports, Science and Technology of Japan (MEXT), which was in effect from April 2020 through 2022, the number of English words introduced throughout ten years (from the $3^{\text {rd }}$ year of elementary school till the $3^{\text {rd }}$ year of senior high school) increases from 3000 words to 4000 - 5000 words, which may make the burden too heavy for JLEs. Thus, nowadays, there is a growing interest for JLEs in search of effective ways of learning English vocabulary. Based on these educational backgrounds, this study attempts to find out an efficient vocabulary learning method for the JLEs in Japan.

Let us briefly describe the organization of this paper: In the Background section following the Introduction, the authors will discuss the type of learning English conditions in Japan, explicit and implicit learning in the classroom, and a review of related previous studies. Then, the authors will explain the procedure of three longitudinal experiments they conducted. After the experiment section, results and discussion of the experiments follow. Finally, the authors will address some proposals for teaching and learning English vocabulary in Japan. Whatever teaching method an English language teacher in Japan adopts, the method must be suited for learning conditions JLEs face. They are shown in (1).

(1) a. JLEs learn English from teachers by using textbooks in the classroom. b. In most of the cases, teachers are nonnative English speakers, that is, Japanese teachers of English (JTEs).

c. Lesson hours for English are limited: twice a week at elementary school and four or five times a week at high school for 35 weeks a year, which cannot be said to be enough for acquiring a foreign language subconsciously.

d. Usually there are over thirty students in the classroom, and there is a limited opportunity to receive the one-to-one instruction from the teacher.

e. There can be a big difference of English proficiency among the students even in the same classroom. It is rather hard for teachers to decide which level of the students they should focus on.

f. Students must learn new English words as well as new English grammar one after the other following the order of the textbook.

g. Students are expected to learn the four skills, reading, writing, listening and speaking, with equal value and time.

Teachers in Japan must find an effective and easy way to practice a teaching method by taking these learning conditions into account. Otherwise, the method would be useless for JLEs. Considering the learning conditions shown in (1), the authors will propose the method of learning English words through reading activities. A reading activity in the classroom at junior and senior high schools as well as at university probably serves the major opportunity for JLEs to come across a wide range of new English words. They can learn and enlarge their vocabulary size more at the reading activity than at the other activities (listening, speaking and writing) because they can encounter many words visually when they read textbooks. Thus, in the experiment of this study, the authors decided to make use of the reading classes when JLEs learn new English words. Learning new words through the reading activities can be a most realizable way of teaching and learning vocabulary in Japan. 


\section{Explicit and Implicit Learning}

There are essentially two types of learning strategy when we learn a foreign language: explicit learning and implicit learning. Explicit learning is defined as "explicit learning through the focused study of words" (Schmitt, 2000, p.116). In explicit vocabulary learning, L2 learners may focus their attention directly on new L2 words through the input materials. They will acquire new L2 words with activities that activate the vocabulary learning process. On the other hand, implicit learning is defined as learning "through the exposure when one's attention is focused on the use of language, rather than the learning itself" (Schmitt, 2000, p.116). In implicit L2 vocabulary learning, they will acquire new L2 words through mere exposure to the input materials without conscious intention to learn.

It is interesting to know which learning method, explicit learning or implicit learning, is more effective for JLEs to learn new English words who are under the learning environments described in (1). As will be described below, there are two opposite opinions. Some researchers claim that L2 learners can attain more knowledge from the explicit vocabulary learning, while others take the opposite side.

\section{Explicit Learning is better Than Implicit Learning}

Explicit L2 vocabulary learning by looking up words in a dictionary. There are studies that claim that explicit learning is more effective than implicit learning. Marzban and Kamalian (2013) compared the effect of explicit vocabulary learning with that of implicit vocabulary learning by using Iranian university students learning English as a Foreign Language (EFL). In this experiment, three groups of the participants received different treatments. The participants of the first group were given reading passages and were told to answer comprehension questions of the passages, which means that they were given the implicit learning method in terms of vocabulary learning. The participants of the second group were given a marginal glossary of the target words in the passages, which means that the participants learned the words explicitly. The participants of the third group were told to check the target words in the passages with a dictionary, which is another explicit learning method for learning vocabulary. After the five sessions, a posttest was administered by using a multiplechoice vocabulary test to compare how much the participants of the three groups learned the words respectively.

The results showed that both explicit groups performed better than the implicit learning group. Moreover, the third group, which used a dictionary, indicated the most effective result among the three groups. The findings of Marzban and Kamalian (2013) provide support for the effectiveness of the explicit learning method in learning L2 vocabulary. What is more, the use of a dictionary can be a good way of learning L2 words. (See also Mizarii (2012) and Yagoubi and Seyyedi (2017) for the similar experimental results).

\section{Explicit L2 vocabulary learning} through cloze task. There are studies that indicate the effectiveness of the use of a cloze task under the explicit L2 vocabulary learning method. Khoii and Poorafshari (2015), for example, compared the effect of a simple text-reading task with that of a cloze test task for L2 vocabulary learning. Their participants were 70 Iranian learners of English. They were divided into an 
experimental group and a control group. During the 10-session treatment, 10 cloze tasks were used for the experimental group. The participants in the experimental group were told to read the 10 passages, and then complete the cloze task cooperatively with other learners and try to fill out the deleted words for each blank. On the other hand, participants in the control group were also told to read the same 10 passages for the purpose of the comprehension of the text as the experimental group did, but they did it without any blanks.

The pretest and the posttest mean scores of the vocabulary test were compared between the two groups. The test results showed that the experimental group gained a significant amount of vocabulary as compared with that of the control group. A mean score of the pretest for the experimental group was 15.6 points and that of the posttest was 33.7 points out of 40 points. There was an increase of 18.1 points from the pretest to the posttest. On the other hand, a mean score of the pretest for the control group was 15.5 points and that of the posttest was 16.3 out of 40 points. Thus, the findings of the study shed light on the effectiveness of the cloze test task with explicit instruction for L2 vocabulary enhancement in the reading class (See also Laufer and Osimo (1991) for the effectiveness of the cloze test task).

\section{Explicit L2 vocabulary learning} through word test. Some studies supporting explicit learning also claim that a word test is an effective learning method for L2 vocabulary. For example, Karpicke and Roediger (2008) investigated the effect of repeated studying and repeated testing by using American university students as participants. Their participants were told to learn a list of 40 L2 Swahili- L1 English word pairs. Participants were first repeatedly exposed to L2 Swahili-L1 English word pairs on computer screens (i.e., Repeated exposure). Then, they took a word test several times. In the word test, L2 Swahili words appeared on the computer screen and the participants were told to type the meaning of these Swahili words into L1 English with the computer keyboards (i.e., Repeated typing). These phases were repeated four times during the treatment session. Then all the participants were tested on their retention of the target words one week later.

The results of the experiment showed that Repeated exposure had no effect at the delayed posttest. On the other hand, Repeated typing had a significant effect at the delayed posttest compared with the performance before the treatment. Therefore, Karpicke and Roediger (2008) claim that taking an L2 into L1 translation test by typing L1 meaning on the keyboard several times can be effective for learners to learn L2 words. They also claim that taking a word translation test repeatedly has a 'testing effect', which is said to strengthen L2 learner's memory for promoting vocabulary learning.

A phenomenon in which learning can be effectively performed by testing the content to be learned repeatedly is called testing effect. This phenomenon was first advocated by the researchers such as Abbott (1909). It seems that the testing effect can activate L2 learners' retrieval processes that help them to store vocabulary effectively in their mind. Thus, findings of Karpicke and Roediger (2008) indicate that learners who experience the word tests during the lessons could retain more L2 words than those who are repeatedly exposed to L2-L1 word pairs. Researchers such as Sökmen (1997) and Mochizuki, Aizawa and Tono (2003) also address the same claim. Thus, the use of word test with repetition in the classroom could be one of the effective explicit learning methods in L2 vocabulary learning. 


\section{Implicit Learning is Better Than Explicit Learning}

Implicit L2 vocabulary learning through reading short stories. There are studies which claim that implicit vocabulary learning is more effective than explicit vocabulary learning. Let us review these studies. Rashidi and Adivi (2010), for example, compared the effect of implicit vocabulary learning with that of explicit vocabulary learning by recruiting 40 Iranian learners of English. The participants were divided into an experimental group and a control group. Those who were in the experimental group were assigned to read five short stories to learn the vocabulary implicitly. On the other hand, participants in the control group explicitly learned the target words by using the Presentation, Practice, and Production (PPP) method. The participants in the control group did not use the short stories. Then, a posttest was held. It was a multiplechoice word test asking the participants to choose the most appropriate meaning of a target word from a set of four choices written

Implicit L2 vocabulary learning through narrow reading. Khamesipour (2015) compared the effect of implicit vocabulary learning through narrow reading, which means to read multiple texts related to a particular topic, with that of explicit vocabulary learning which was done through pre-learning definitions of the words before reading. The research involved a total of 30 Iranian EFL university learners as participants. All the participants were supposed to learn the target words in two different ways. In the first phase, they took a pretest prepared for the explicit vocabulary learning treatment. Then, they explicitly learned the target words by using pre-learning definitions of the target words in L2 English.

The results showed that the experimental group (implicit group) learned more words than the control group (explicit group). To explain the results, Rashidi and Adivi (2010) argue that the participants had to read the texts for the purpose of comprehending the contents, so they must have paid attention to the contextual clues to infer the meaning of the unknown words. They further argue that these results are likely to due to the repeated exposure to the target words in the five short stories. Since the target words tested were mainly related to the general theme of these stories, the participants in the experimental group (implicit group) had quite a few encounters with the same target words through the stories. The findings of their study indicate that the reading of short stories constructed with similar words can facilitate implicit L2 vocabulary learning.

before reading the three texts. After three sessions of this treatment (explicit learning), the posttest (explicit vocabulary posttest) was given to them. In the second phase, they took another pretest prepared for the implicit vocabulary learning treatment. After taking the pretest, they were assigned to read six texts selected for narrow reading without any focus and explanation on the target words. After six sessions of the treatment (implicit learning), the posttest (implicit vocabulary posttest) was conducted.

The results showed that the participants performed better with implicit vocabulary learning than with explicit vocabulary learning. The findings also indicate that repeated

BEYOND WORDS Vol. 9 No.1 May 2021 Graduate School, Widya Mandala Catholic University Surabaya 
exposure to the target words can play an important role in learning L2 vocabulary.

\section{Summary of Previous Studies}

Let us critically summarize the findings and discussions what we have argued so far. Marzban and Kamalian (2013) show that the explicit L2 vocabulary learning method they used is more effective than the implicit L2 vocabulary learning method. Regarding the use of word-focused tasks, Khoii and Poorafsha (2015) indicate that the cloze task is more effective than the text-reading task. However, these studies did not examine the issue of long-term vocabulary retention. It should be necessary to examine not only shortterm vocabulary attainment but also long-term retention by conducting a delayed posttest after a long interval (See also Waring and Takaki (2003) for the same claim). Additionally, Karpicke and Rodiger (2008) mention that the explicit learning method by using word tests has a significant impact on L2 vocabulary learning. However, the study did not design its effect in relation to a reading-centered activity.

\section{Research Method}

\section{Purpose of the study}

The purpose of the study is to compare the effects of three different methods of learning L2 vocabulary carried out through English reading lessons. The authors will examine which type of vocabulary learning is the most effective for JLEs.

\section{Participants}

A total of 93 university JLEs participated in the study. There were 67 JLEs in the experimental group and 26 JLEs in the control group. There were 4 classes that were selected to be the participants of this study, and students were randomly assigned to be in the experimental group and the control group by
Thus, it is not yet clear of a validity of L2 vocabulary learning through reading activities, which the authors will conduct in this experiment.

On the other hand, Rashidi and Adivi (2010) show that learning L2 vocabulary implicitly through reading short stories is better than learning L2 vocabulary explicitly. Similarly, Khamesipour (2015) report that implicit vocabulary learning through narrow reading is more effective than explicit vocabulary learning through the pre-learning definition of the L2 words. However, a further study should be done to compare the effect of implicit L2 vocabulary learning with that of explicit L2 vocabulary learning because we have not yet fully reached the conclusion which method is a better method under the English learning environment in Japan as shown in (1).

With these in mind, by selecting three vocabulary learning methods, the present study will attempt to find out the most effective way of learning L2 vocabulary in reading classes.

the researchers. They were all first-year university students in Japan and were nonEnglish majors enrolled in general English reading classes. Their English proficiency level based on the university's independent placement test is comparable to a range of 400 to 450 in TOEIC. Moreover, 67 participants in the experimental group were further divided into three subgroups (Group A, Group B and Group C) in order to give different learning conditions to learn the target English words. These three groups were Group A: the Implicit Vocabulary Learning Group with Questions in English/Answers in English Task $(n=20)$, Group B: the Explicit Vocabulary Learning 
Group with Cloze Test Task $(n=24)$, and Group C: the Explicit Vocabulary Learning Group with Multiple-choice Word Test Task $(n=23)$. In addition, there was a control group: CG $(n=26)$.

\section{Materials}

All the participants in the three experimental groups were expected to read through the English textbook assigned by the authors. It was "Snow Falling on Cedars" originally written by David Guterson and retold by Christopher Tribble. It is one of the graded reader series published by Pearson English Readers, which are targeted for university students as well as adult learners of English. The textbook has 107 pages and includes 3000 head words. All the participants in the three experimental groups began to read it from the second week of the class (Week 2) and finished reading it on the $13^{\text {th }}$ week (Week 13). See Figure 1.

\section{Procedure}

Selection of 110 English words tested. One hundred and ten English words were tested at the pretest, immediate posttest and delayed posttest in the form of "translating the English words into Japanese". These 110 target words all appear in the textbook. They were selected by using the tryout lessons given by one of the authors in the previous year, 2019. He asked 20 non-English major Japanese students at the university who would not participate in this experiment to translate 200 English words, which were all in "Snow Falling on Cedars", into Japanese equivalents. Then, the authors collected the answer sheets from these 20 students to check the results. They decided that the words over $50 \%$ of the students answered correctly would not be used in this experiment. As a result, 110 target words were selected for the present vocabulary test.

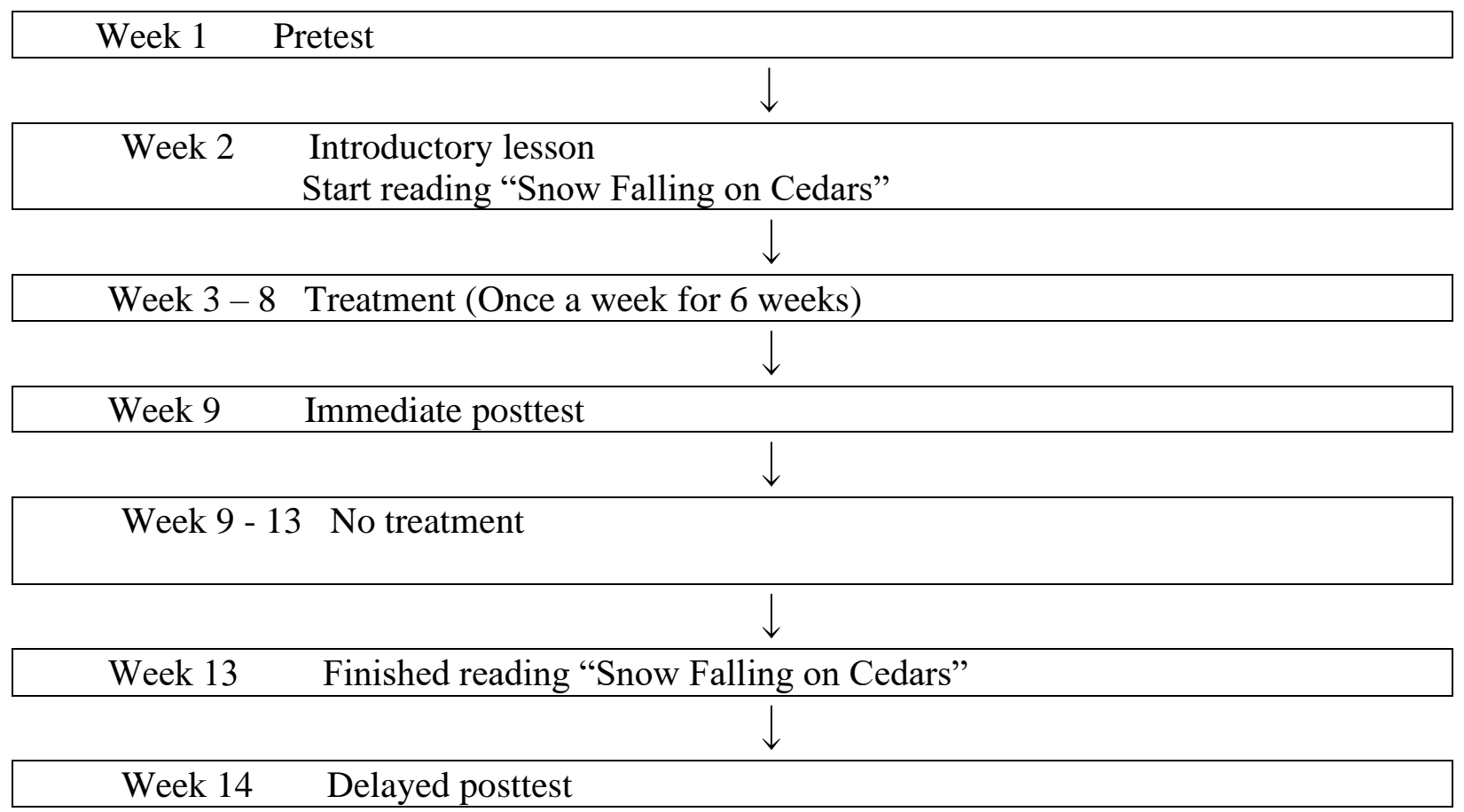

Figure 1. Overall schedule of the experiment

BEYOND WORDS Vol. 9 No.1 May 2021 Graduate School, Widya Mandala Catholic University Surabaya 

Schedule for the Experiment. An overall schedule for the whole experimental design is shown in Figure 1. On week 1, all the participants took the pretest. They were asked to translate the 110 English target words into Japanese. Although there was no time limitation for completing the answers, the participants finished the task within 30 minutes. Then, the answer sheets were collected to record their scores. On week 2, an introductory lesson on the historical background of the textbook, "Snow Falling on Cedars", was given by the authors, and the participants began to read the textbook following their teacher's directions. From Week 3 to Week 8, the participants in each experimental group received different types of treatments once a week for six consecutive weeks.

Group A. In Group A, every time after reading several chapters of the textbook, the participants were engaged in the reading comprehension tasks about the story of the textbook. They worked individually in completing the comprehension questions about the contents of the textbook. See Table 1. They grappled with questions written in English.

\section{Table 1}

\section{Examples of Comprehension Questions for Group A}

\begin{tabular}{|c|c|c|}
\hline Description & True or False & Multiple-choice Qs \\
\hline $\begin{array}{l}\text { Q: Write short answers to these } \\
\text { questions. }\end{array}$ & $\begin{array}{l}\text { Q: Are these sentences true (T) } \\
\text { or false (F)? } \\
\text { a). Ishmael was injured in the } \\
\text { war. } \\
\text { b). After the war, he found it } \\
\text { difficult to settle in San Piedro. } \\
\text { c). Ishmael expects the sheriff to } \\
\text { lie to him. } \\
\text { d). The sheriff is sure that Carl } \\
\text { Heine was murdered. }\end{array}$ & $\begin{array}{l}\text { Q: Who is talking? Who are } \\
\text { they talking to? } \\
\text { a). 'A limited research.' } \\
\text { b). 'In a half-hour you might be in } \\
\text { Canada. } \\
\text { c). 'I do it out of habit.' } \\
\text { d). 'Did you hear any part of their } \\
\text { conversation?' }\end{array}$ \\
\hline
\end{tabular}

BEYOND WORDS Vol. 9 No.1 May 2021 Graduate School, Widya Mandala Catholic University Surabaya
They were supposed to answer them in English. The comprehension questions were divided into six-chapter chunks which included whquestions, true or false questions and multiplechoice questions. There were 10 to 20 questions at one time ready for the participants. They were allowed to use a bilingual dictionary to answer the questions.

Then, the participants compared their answers with each other. They were asked to take turns in reading aloud the answers to the class in pairs by identifying the passages that illustrated the answers in the textbook to justify their answers for the questions given. Then, one of the authors gave answers and feedback to the participants on the content of the textbook without any focus on the words that appeared. The materials used for the comprehension questions were collected at the end of each lesson. During these activities, there was little explicit focus on vocabulary. Thus, as far as the vocabulary learning is concerned, it can be said that, most of the time, the participants implicitly learned English words they were unfamiliar with by reading the textbook and answering the comprehension questions in English. 


\begin{tabular}{|c|c|c|}
\hline Description & True or False & Multiple-choice Qs \\
\hline $\begin{array}{l}\text { Q: Write short answers to these } \\
\text { questions. }\end{array}$ & $\begin{array}{l}\text { Q: Are these sentences true }(T) \text { or } \\
\text { false }(F) \text { ? }\end{array}$ & $\begin{array}{l}\text { Q: Who is talking? Who } \\
\text { are they talking to? }\end{array}$ \\
\hline $\begin{array}{l}\text { a). What help does Ishmael need to } \\
\text { write about the weather in his }\end{array}$ & a). Ishmael was injured in the war. & a). 'A limited research.' \\
\hline paper? & $\begin{array}{l}\text { b). After the war, he found it } \\
\text { difficult to settle in San Piedro. }\end{array}$ & $\begin{array}{l}\text { b). 'In a half-hour you might } \\
\text { be in Canada. }\end{array}$ \\
\hline $\begin{array}{l}\text { b). Who is Ishmael able to help on } \\
\text { the road out of the town? }\end{array}$ & $\begin{array}{l}\text { c). Ishmael expects the sheriff to lie } \\
\text { to him. }\end{array}$ & c). 'I do it out of habit.' \\
\hline $\begin{array}{l}\text { c). How does Evan Powell help } \\
\text { Ishmael? }\end{array}$ & $\begin{array}{l}\text { d). The sheriff is sure that Carl } \\
\text { Heine was murdered. }\end{array}$ & $\begin{array}{l}\text { d). 'Did you hear any part of } \\
\text { their conversation?' }\end{array}$ \\
\hline $\begin{array}{l}\text { d). Why is it difficult for Ishmael's } \\
\text { mother to help her son? }\end{array}$ & & \\
\hline
\end{tabular}

Group B. In Group B, every time after reading several chapters of the textbook, the participants were assigned to complete cloze tasks which were based on a series of summaries of the textbook which contained the target words. See Table 2. They were given six cloze tasks with blanks of target words in it. As a form of the list, the target words were given below the cloze test at random as choices. Each cloze task included 10 to 20 target words. At first, the participants were asked to use a bilingual dictionary to look up the L1 meaning of each target word

\section{Table 2}

\section{An Example of the Cloze Task for Group B}

One day Kazuo Miyamoto attended at a (1.) as the (2.)

Ishmael Chambers, the local reporter, was in the (3.) He is acquainted with Kabuo's wife. Art Moran, the county (4.) , found that there was a fishing boat in White Sand Bay. There was nobody on the boat, but there

was a net underwater. Carl Heine's dead body that the left (5.) sank from the net was found.

Kabuo Miyamoto's lawyer, Nels Gudmundsson asked some questions to the sheriff. One of the questions was about a (6.) D-6 battery that was found in the (7.) 's battery holder that should only be fitted with a D-8 battery. The sheriff explained that the battery holder was (8.) away to make room for the D-6 battery. Unexpectedly, the (9.) 's boat had the exact D-6 battery and he did not have any spare battery which was quite suspicious. Lastly, the lawyer asked the sheriff if he had any (10.) that there was a possibility that the man banged his head after his death as he was bringing him into the boat.

(banged, skull, sheriff, accused, uncertainty, court, spare, deceased, defendant, trial) 
Group C. In Group C, every time after reading several chapters of the textbook, the participants took the multiple-choice English word test once a week for six weeks which contained the target words. See Table 3 . The participants had been told beforehand that they would take the multiple-choice English word test. The 110 target words were divided into the first half part (version $\mathrm{A}$ ) and the second half part (version B), consisting of 55 words for each version. The multiple-choice
English word test was given out to the participants repetitively in the sequence of "(version) $\mathrm{A} \rightarrow$ (version) $\mathrm{B} \rightarrow \mathrm{B} \rightarrow \mathrm{A} \rightarrow \mathrm{A} \rightarrow \mathrm{B}$ " order. They were asked to choose the most appropriate meaning of the target words from a set of four candidates translated into Japanese. This test was carried out at the beginning of each lesson followed by peerscoring. The answer sheets were collected each time after they had marked their scores.

Table 3

Examples of Multiple-Choice English Word Test for Group C

(1) The man accused of robbery was put on trial in Chicago.
(1)裁判
(2)施設
(3)執行猶予
(4)留置場

(2) The accused sat in a box opposite the jury.
(1)専門家
(2)被告人
(3)犯人
(4)鑑定士

(3) Both lawyers gave very convincing closing arguments to the court.
(1)記者
(2)審判
(3)法廷
(4)競技場

(4) The sheriff gave the young lady a speeding ticket the night before.
(1)管理人
(2)保安官
(3)修理人
(4)司令官

(5) A skull of a monkey was on the anthropologist's fireplace.
(1)模型
(2)剥製
(3)頭蓋骨
(4)見本

Properties of the three experimental treatment for each group can be applied to groups are summarized in Table 4 . In the term 'Task type', whether a particular implicit learning or explicit learning is shown.

\section{Table 4}

Three Different Types of Treatments for the Experimental Groups

\begin{tabular}{llll}
\hline Group & Task Type & Class & Task \\
\hline Group A & Implicit & Reading-centered & Questions-Answers in the English Task \\
Group B & Explicit & Reading-centered & Cloze task \\
Group C & Explicit & Reading-centered & Multiple-choice word task
\end{tabular}

After the treatment session. On Week 9, one week after the final treatment, the participants took the immediate posttest. The participants of all the groups had not been informed that they would take the vocabulary test again as the immediate posttest. As same 
as the pretest, the participants were asked to translate the 110 English words into Japanese. The order of the words tested was randomly scrambled. After the final treatment (Week 8) was finished, no treatment was given to the three experimental groups for five weeks (Week 9 - Week 13). Then, on Week 14, all the participants took the delayed posttest. Once again, they had not been informed that they would take the delayed posttest. The order of the words was randomly scrambled again. In the test, they were asked to translate the 110 English words into Japanese.

Participants in the control group did not use the textbook, used by the experimental

\section{Results and Discussion}

Results of Pretest, Immediate Posttest, and Delayed Posttest

Table 5 shows the results of the experiment: the number of participants of the four groups (n), mean scores (M), percentages of correct answers (\%) and standard deviation group nor did receive any additional or extraordinary vocabulary teaching. The control group worked under normal conditions focusing on reading comprehension of informational texts every week. This group took the same pretest, immediate posttest and delayed posttest as the experimental groups.

\section{Research Question}

The following research question (RQ) is addressed in this study.

RQ: Which is the most effective L2

vocabulary learning method among the three, a method used by Group A, Group B or Group C?

Table 5

Results of the pretest, immediate posttest and delayed posttest

$\underline{\text { Pretest }} \quad \underline{\text { Immediate posttest }}$ Delayed posttest

\begin{tabular}{lcrrrrrrrrr} 
Group & $n$ & $M$ & $\%$ & $S D$ & $M$ & $\%$ & $S D$ & $M$ & $\%$ & $S D$ \\
\hline Group A & 20 & 21.3 & 19.3 & 7.2 & 38.3 & 34.5 & 13.2 & 35.6 & 32.2 & 10.7 \\
Group B & 24 & 21.5 & 19.5 & 8.2 & 61.6 & 56.0 & 17.0 & 59.7 & 54.2 & 13.6 \\
Group C & 23 & 19.4 & 17.6 & 11.6 & 91.4 & 83.0 & 18.1 & 86.8 & 78.9 & 16.6 \\
CG & 26 & 19.7 & 17.9 & 7.9 & 22.1 & 20.0 & 10.4 & 22.3 & 20.2 & 8.6 \\
\hline
\end{tabular}

Note: The maximum score per test was 110. 


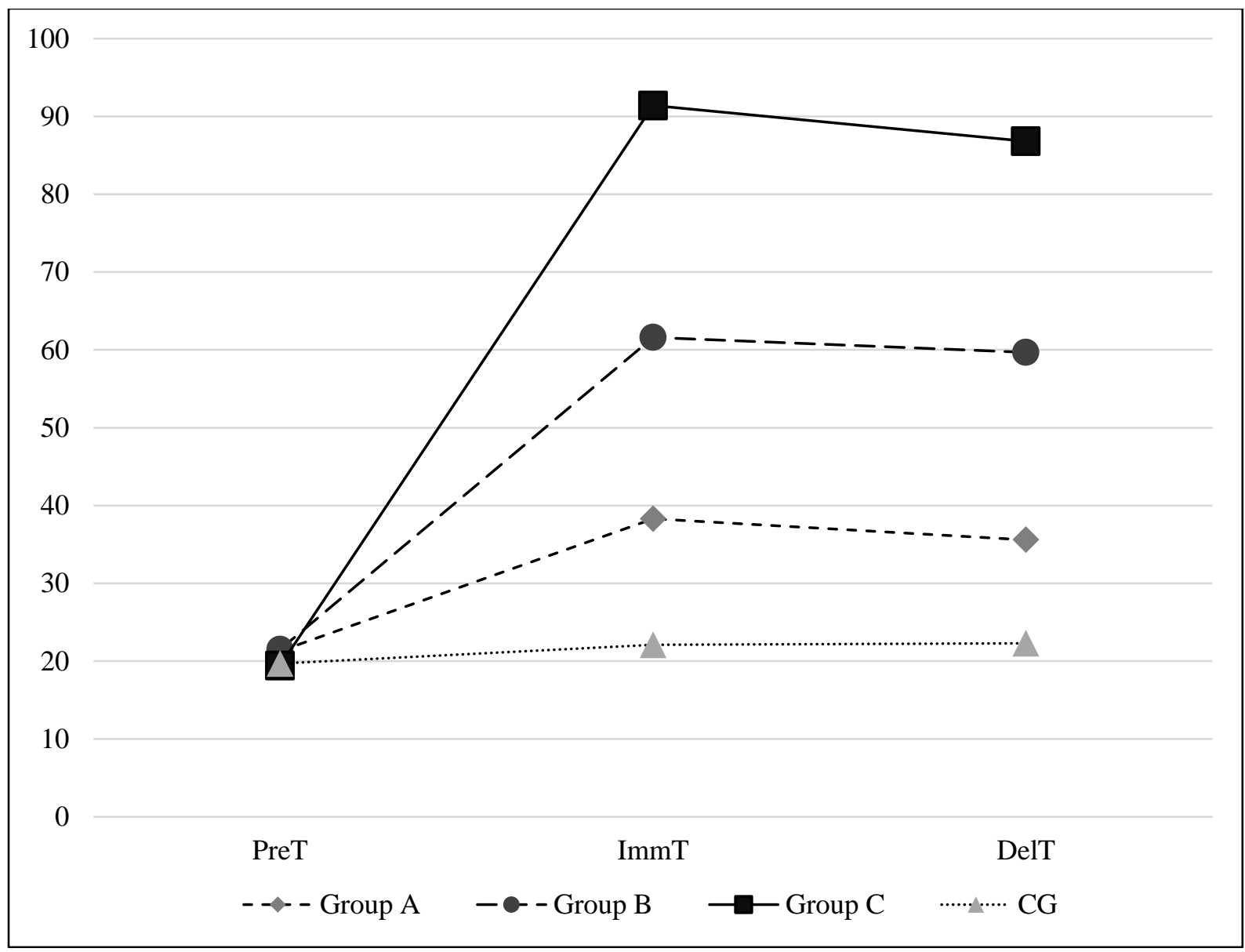

Note: PreT $=$ Pretest, ImmT $=$ Immediate posttest, DelT $=$ Delayed Posttest.

Figure 2. Results of the pretest, immediate posttest, and delayed posttest.

The results of a two-way mixed ANOVA (Groups: Group A, Group B, Group $\mathrm{C}$ and $\mathrm{CG} \times$ Tests (Pretest, Immediate posttest and Delayed posttest) indicate that the main effect between Groups was statistically significant $(F(3,89)=81.63, p<.001, \mathrm{ES}: \eta p 2$ $=.73)$. The main effects between Tests was statistically significant $(F(1.78,158.48)=$ 454.78, $p<.001$, ES: $\eta p 2=.84)$. Also, the interaction of Groups and Tests was found to be significant $(F=(5.34,458.48)=100.88, p$ $<.001$, ES: $\eta p 2=.77)$. Thus, the simple main effect of Tests (pretest, immediate posttest and delayed posttest) in each level of Groups (Group A, Group B, Group C, and CG) and simple main effect of Groups in each level of
Groups were conducted. Let us carefully discuss these results by each group.

Results of Group A. In the results of Group A, the mean score of the pretest was 21.3, that of the immediate posttest was 38.3. Compared with the pretest, the mean score of the immediate posttest increased by 17.0 points. Thereafter, the percentage of the correct answer progressed from $19.3 \%$ for the pretest to $34.5 \%$ for the immediate posttest. There was an increase of $15.3 \%$. On the other hand, the mean score of the delayed posttest was 35.6. Therefore, compared with the immediate posttest, the mean score of the delayed posttest decreased by 2.7 points. The correct percentage of the delayed posttest was

BEYOND WORDS Vol. 9 No.1 May 2021 Graduate School, Widya Mandala Catholic University Surabaya 
$32.3 \%$, which was $2.2 \%$ less than the immediate posttest. Hence, compared with the pretest, the mean score of the delayed posttest was higher than that of the pretest by 14.3 points. The correct percentage of the delayed posttest increased by $12.9 \%$ from that of the pretest.

The result of the simple main effect of Tests show that the differences of the mean scores among the pretest, immediate posttest and the delayed posttest for Group A were statistically significant $(F(2,38)=53.17, p$ $<.001$, ES: $\eta p 2=.74)$. Multiple comparisons based on SRB (Sequentially Rejective Bonferoni) indicates that the mean score of the immediate posttest of Group A was significantly higher than that of the pretest $(p$ $<.001)$, and no significant difference was found between the immediate posttest and the delayed posttest $(p=0.16)$. The mean score of the delayed posttest was statistically higher than that of the pretest $(p<.001)$.

These results indicate that the participants in Group A learned some new L2 words and maintained the score for six weeks. That is to say, they were implicitly able to learn L2 words through reading the textbook and practicing Questions and Answers for the contents in English. Nevertheless, the amount of vocabulary learned through the method Group A adopted was found to be small compared with the other two methods. In this respect, the results of the present study are consistent with those of Marzban and Kamalian (2013), which was discussed above. Thus, the implicit vocabulary learning method with the Questions/Answers in English task was effective to some extent, but may not seem to be impactful for JLEs to greatly improve their L2 vocabulary size.
Results of Group B. In the results of Group B, the mean score of the pretest was 21.5, and that of the immediate posttest was 61.6. Thus, the mean score increased by 40.1 from the pretest to the immediate posttest. Then, the percentages of the correct answers improved from $19.5 \%$ for the pretest to $56.0 \%$ for the immediate posttest. There was an increase of $36.5 \%$. On the other hand, the mean score of the delayed posttest was 59.7. Hence, compared with the immediate posttest, the mean score of the delayed posttest decreased by 1.9 points. The percentage of correct answers of the delayed posttest dropped by $1.8 \%$ with $54.2 \%$ from the immediate posttest. Moreover, compared with the pretest, the mean score of the delayed posttest was higher than that of the pretest by 38.2 points. The correct percentage of the delayed posttest increased by $34.7 \%$ with $54.2 \%$ from the pretest.

The results of the simple main effect of Tests show that the differences of mean scores between the pretest, immediate posttest and delayed posttest for Group B were also found to be statistically significant $(F(1.58,36.28)=$ 152.25, $p<.001$, ED: $\eta p 2=.87)$. Multiple comparisons based on SRB indicates that the mean score of the immediate postest was significantly higher than that of the pretest ( $p$ $<.001$ ), and there was no significant difference between the immediate posttest and the delayed posttest $(p=0.48)$. The delayed posttest was statistically higher than the pretest $(p<.001)$.

These results show that the participants in Group B averagely gained 40.1 target words out of 110 words through the reading comprehension activity with the explicit cloze tasks, and they retained their performance for six weeks. The results of the present study 
filled the gap of the lack of delayed posttest data in Khoii and Poorafshari (2015). Thus, the findings indicate that L2 vocabulary learning with the explicit cloze task activity can be effective, and its effect can be durable for at least six weeks.

Results of Group C. In the results of Group C, the mean score of the pretest was 19.4 , and that of the immediate posttest was 91.4. Thus, compared with the mean score of the pretest, the mean score of the immediate posttest increased by 72.0 points. The percentages of the correct answers increased from $17.6 \%$ for the pretest to $83.0 \%$ for the immediate posttest. There was an increase of $65.4 \%$. On the other hand, the mean score of the delayed posttest was 86.8. Thus, compared with the immediate posttest, the mean score of the delayed posttest was a 4.6 points decrease. The correct percentage of the delayed posttest declined by $4.1 \%$ with $78.9 \%$ from the immediate posttest. Additionally, the mean score of the delayed posttest was higher than that of the pretest by 67.4 points. The correct percentage of the delayed posttest increased by $61.3 \%$ with $78.9 \%$ from the pretest.

The results of the simple main effect of Tests show that the differences of mean scores between the pretest, immediate posttest and delayed posttest for Group C were statistically significant $(F(2,44)=276.99, p<.001, \mathrm{ES}$ : $\eta p 2=.93)$. Multiple comparisons based on SRB indicates that the mean score of the immediate posttest for Group C was significantly higher than that of the pretest ( $p$ $<.001$ ), and no statistical difference was observed between the immediate posttest and the delayed posttest $(p=0.21)$. The delayed posttest was statistically higher than the pretest $(p<.001)$.
These results show that the participants in Group $\mathrm{C}$ gained a significant amount of vocabulary with a 72.0 points increase through the reading comprehension with the explicit multiple-choice English word tests, and maintained their performance level for six weeks. As well as the findings of Karpicke and Roediger (2008), the results of the present study also demonstrate a strong effect of the word test conducted in the classroom. We believe that repeated retrieval of word knowledge by using the test trials has a positive effect on L2 vocabulary learning with a long-term retention for university JLEs in the reading-centered classroom in Japan.

Results of Control Group. In the results of CG, the mean score of the pretest was 19.7, and that of the immediate posttest was 22.1. The mean score increased by 2.4 points from the pretest to the immediate posttest. The percentages of correct answers increased from $17.9 \%$ for the pretest to $20.0 \%$ for the immediate posttest. On the other hand, the mean score of the delayed posttest was 22.3, and that of the immediate posttest was 22.1. There was an increase of 0.2 points. Furthermore, the mean score of the delayed posttest was higher than that of the pretest by 2.6 points. The correct percentage of the delayed posttest increased by $2.3 \%$ from the pretest.

However, the results of the simple main effect of Tests show that there were no significant differences of mean scores between the pretest, immediate posttest and delayed posttest for $\mathrm{CG}(F(2,50)=2.11, p=.13, \mathrm{ES}$ : $\eta \mathrm{p} 2=.08)$. These results show that there are no statistical differences among the pretest, immediate posttest and delayed posttest in the control group. Therefore, the improvements 
observed in the three experimental groups were attributed to the effects of the treatments adopted in this experiment.

\section{Group Comparison}

Now let us discuss the results of the pretest, immediate posttest, and delayed posttest among the groups (Group A, Group B, Group $\mathrm{C}$ and $\mathrm{CG}$ ). The interaction of Groups and Tests was found to be significant $(F=$ $(5.34,158.48)=100.88, p<.001, \mathrm{ES}: \eta \mathrm{p} 2=$ $.77)$. Thus, further analysis was conducted to determine the simple main effect of tests and groups. The result of the simple main effect of the pretests among groups (Group A, Group B, Group $\mathrm{C}$, and $\mathrm{CG})$ was not significant $(F(3,89)$ $=.35, p=.79, \mathrm{ES}: \eta \mathrm{p} 2=.01)$. This result indicates that the mean scores of groups show no statistical differences at the pretest with 21.3 for Group A, 21.5 for Group B, 19.4 for Group C and 19.7 for CG respectively. Thus, regarding the participants' English language proficiency levels at the pretest, they were homogeneous.

On the other hand, the result of the simple main effect of the immediate posttests was statistically significant $(F(3,89)=96.00$, $p<.001$, ES: $\eta p 2=.76)$. Multiple comparisons based on SRB indicates that Group $C$ had the statistically highest score with 91.4 in the immediate posttest followed by Group B with 61.6, Group A with 38.3 and CG with 22.1 ( $p$ $<.001)$ respectively. Moreover, the result of the simple main effect of the delayed posttests was statistically significant $(F(3,89)=118.01, p<$ .001 , ES: $\eta p 2=.80)$. Correspondingly, multiple comparisons based on SRB indicates that Group $C$ had the statistically highest score in the delayed posttest with 86.8 followed by Group B with 59.7, Group A with 35.6 and CG with $22.3(p<.001)$.
In summary, the results for the group comparison show that Group $\mathrm{C}$ had the highest scores with 91.4 in the immediate posttest and 86.8 in the delayed posttest. Then, Group B had the second highest scores with 61.6 in the immediate posttest and 59.7 in the delayed posttest. On the other hand, Group A had the least gains of 38.3 in the immediate posttest and 35.6 in the delayed posttest.

\section{Discussion}

The research question in the present study is that: Which is the most effective L2 vocabulary learning method among the three, the method used by Group A, Group B or Group C? We answer the research question below. The results obtained from the experiment show that there are improvements in all the three groups, and that they maintained their effects till the delayed posttest (for six weeks). Thus, the results indicate that the three methods we adopted all had positive effects on L2 vocabulary learning. However, the result of the group comparisons shows that the participants in Group C performed much better than those in the other two groups. Thus, we have confirmed that L2 vocabulary learning with the explicit multiple-choice English word tests at the reading comprehension class was found to be the most effective among the three.

The results also show that those who were in Group B had the second highest scores of the three groups. Therefore, L2 vocabulary learning with the explicit cloze tasks at the reading comprehension class had an impact on JLEs' L2 vocabulary learning. On the other hand, Group A gained the least improvement of the L2 vocabulary among the three groups. Hence, it seems that L2 vocabulary learning through the implicit Questions/Answers in English task at the reading class is not as 
effective as the others for university JLEs. Although the implicit learning method may be effective in the L2 environment where JLEs acquire English in an English-speaking country such as the United States, the authors believe that the explicit learning method is better suited for classroom learning conditions in Japan than the implicit method, where the lesson hours for English are limited.

These results are in line with Khoii and Poorafshari (2015), claiming that incorporating the cloze task into the reading activity was found to be more effective than reading for comprehension purpose. At the same time, the results of the present study support Karpicke and Rodiger (2008), claiming that giving a word test repetitively can lead to effective vocabulary learning. Furthermore, the results indicate that it is more effective to learn new words by directly focusing on the words themselves (i.e., explicit L2 vocabulary learning through a word test) than to learn them by using the context of passages in the textbook (i.e., explicit L2 vocabulary through a cloze task). It is assumed that, as researchers such as Mochizuki, Aizawa and Tono (2003) and Sokemen (1997) claim, repeated word testing in the classroom may provide a good opportunity for L2 learners to explicitly review new words through the exposure to them. Thus, the present study has also shown that giving a word test (a multiplechoice word test in this experiment) can be fairly beneficial for developing L2 learners' vocabulary gain.

On the other hand, the results of the present study are inconsistent with those of Rashidi and Adivi (2010) and Khamesipour (2015). Rashidi and Avidi (2010) claim that implicit vocabulary learning is more effective than explicit vocabulary learning, which shows the opposite result from the present study. It seems that this controversial result is attributed to the absence of the textbook for the explicit group in Rashidi and Avidi (2010). They employed the PPP method for this group without any textbooks. Generally speaking, the purpose of the PPP method is to learn/teach the 'textbook,' and the focus is mainly on the learning/teaching of grammar, not vocabulary. Hence, using this kind of learning-teaching method without a textbook may defeat the purpose of the PPP method. It is not wellsuited to learn vocabulary explicitly without any textbooks. Khamesipour (2015) also claim that implicit learning through narrow reading is more effective than explicit learning through pre-learning definition of L2 words. This result may be due to the fact that the implicit learning group in Khamesipour's study had twice as much time and many repetitions to the target words as the explicit learning group did.

The present research has also clarified that explicit vocabulary learning, in particular using the explicit multiple-choice word test, can maintain vocabulary knowledge for a certain period of time, in this experiment, at least for six weeks. This method can be fairly effective for learning new L2 words with a reading activity. The findings from the study have shed light on the instructional methods as to vocabulary enhancement under the Japanese educational contexts discussed in (1). Then, it is necessary to devise some useful methods for conducting a word test in class. We will discuss the issue in the next section.

\section{Pedagogical Implications}

Some pedagogical implications based on the findings of the present study are discussed. Firstly, the authors believe that incorporating 
the multiple-choice word test into the readingfocused classroom can be available to whatever the school levels are: junior high school, senior high school and university. For example, in a class of "English Communication" at senior high school, which is commonly taught three times a week, teachers can give students opportunities to review English words that they have learned earlier in their textbooks by giving them a review multiple-word test once a week. Teachers do not have to give the students the word test at every class: Once a week is enough. To be specific, it will be effective for the students to review the words in the previous chapter of their textbook by using the multipleword test once a week. The test should be made for the students to be able to complete in 15 minutes otherwise it would be a burden. This can also be a useful warm-up task if it is done before the students begin to read their textbook. Secondly, regarding the grading of the word test, it will be effective to employ a peer or a group scoring method before the students submit their scores to their teachers. This scoring method can lead to the active learning and collaborative learning. Peer reviewing can help facilitate the autonomy of the students as well as they can get feedback on their answers. Also, this method can reduce the burden on the teachers. When this grading method is used, what the teachers do is to collect the word test sheets after students have marked their scores and to make sure that their scoring is done appropriately and to what extent they have achieved their word knowledge.

Lastly, giving a word test on a regular basis can give a clear goal to JLEs about their vocabulary learning. It will motivate them to prepare for the word test at home easily because they know the words they must study, which are the ones they have already learned in the previous chapter.

\section{Conclusion}

As mentioned earlier, the authors' ultimate purpose is to find out the most effective learning/teaching method of L2 vocabulary learning in Japan. Then, as the first step for achieving this purpose, the present study has examined the effectiveness of the three vocabulary learning methods. The research question was that which is the most effective method for JLEs to learn English words through the reading activity in the classroom. The authors designed and conducted three longitudinal experiments. Each experiment had a different learning method for L2 vocabulary. The experimental group was divided into three subgroups. Group A was the Implicit Vocabulary Learning Group with Questions in English/Answers in
English Task, Group B was the Explicit Vocabulary Learning Group with Cloze Test Task, and Group C was the Explicit Vocabulary Learning Group with a Multiplechoice Word Test Task.

The findings obtained from the study show that every treatment the examiners used was effective so that all the experimental groups improved their performances at the immediate posttest and maintained them for six weeks after the last treatment. However, there was a difference concerning the degree of improvement among these three groups. The two groups with explicit learning methods (Groups B and C) scored higher than the group with the implicit learning method (Group A). Moreover, Group C, which adopted the 
multiple-choice word test task, improved more significantly than Group B with the cloze test task. Thus, the authors have concluded that the (multiple-choice) word test in the reading activity can be a fairly effective way to facilitate JLEs' word knowledge as well as their reading ability under the learning conditions which JLEs have in Japan.

Finally, for our future study, the authors will note the following. The present study has not looked into a clear picture of what type of words (that is, for example, such as nouns or verbs, and concrete nouns or abstract nouns, etc.) are learned better than other types of words. Moreover, the study has not examined each participant's individual differences. There must be some developmental differences among each individual. We should examine to what extent the implicit and explicit L2 vocabulary learning are effective on individual learners. Further examination is needed to clarify these issues.

\section{References}

Abbott, E. E. (1909). On the analysis of the factors of recall in the learning process. Psychological Review: Monographs Supplements, 11, 159-177.

Guterson, D. retold by C. Tribble. (2008). Snow Falling on Cedars. Harlow: Pearson Education.

Karpicke, J. D., \& Roediger, H. L. (2008). The critical importance of retrieval for learning. Science, 319, 966-968.

Khamesipour, M. (2015). The effects of explicit and implicit instruction of vocabulary through reading on EFL learners' vocabulary development. Theory and Practice in Language Studies, 5(8), 16201627.

Khoii, R., \& Poorafshari, B. (2011). The impact of cooperative performance on the cloze test on the development of vocabulary knowledge. Retrieved January 12, 2020. From: http//pixel-online-net.

Laufer, B., \& Osimo, H. (1991). Facilitating long-term retention of vocabulary: the second hand cloze. System 19, 217-224.

Marzban, A., \& Kamalian, K. (2013). Effects of implicit versus explicit vocabulary instruction on intermediate EFL learners' vocabulary knowledge. ELT Voice, 3(6), 8495.

Mirzaii, M. (2012). Implicit vs explicit vocabulary learning: Which approach serves long-term recall better? $3 L$ : Language, Linguistics and Literature, The Southeast Asian Journal of English Language Studies, 18(2), 1-12.

Mochizuki, M., Aizawa, K., \& Tono, Y. (2003). Eigo goishidou no shidoumanyuaru [Instructional Manual for English Vocabulary]. Tokyo: Taishukan.

Rashidi, N. \& Adivi, A.G. (2010). Incidental vocabulary learning through comprehension-focused reading of short stories. Journal of English Language Teaching and Learning, 53(217).

Schmitt, N. (2000). Vocabulary in language teaching. Cambridge: Cambridge University Press.

Sökmen, A. J. (1997). Current trends in teaching second language vocabulary. In $\mathrm{N}$. Schmitt \& M. McCarthy (Eds.), Vocabulary, Description, Acquisition and Pedagogy (pp. 237-257). Cambridge: Cambridge University Press.

Waring, R., \& Takaki, M. (2003). At what rate do learners learn and retain new vocabulary from reading a graded reader? Reading in a Foreign Language 15, 130-163.

Yaghoubi, T. S., \& Seyyedi, F. (2017). The effect of explicit and implicit teaching vocabulary on Iranian EFL learners' vocabulary. Studies in English Language and Education, 4(1), 15-25. 